\title{
Working with Nonprofit Organizations in Community Settings: Developing a Code of Ethics for your Organization
}

Elizabeth B. Bolton and Anna Guest-Jelley

\section{Rationale}

The nonprofit organization often overlooks ethics as a critical component of developing the strategic plan, working on the assumption that organizational ethics are implied elsewhere in the plan, or that they have already been written in the statement of values/principles. While it is important to write the statement of principles, a code of ethics takes that information even further; it helps define the unique challenges of people working in nonprofits.

\section{Preparing the Code of Ethics}

Identify who will develop the code of ethics and how they will consult the other stakeholders in the process. The code of ethics does not exist in isolation from other policies, procedures, and elements of the organization-the board of directors, the chief executive officer, staff, and select volunteers should be involved. After a draft is developed, it should be given to everyone in the organization. Note, too, that as the organization changes or matures, the code of ethics may grow to include additional possibilities.

\section{Values Unique to Your Organization}

Many nonprofits share common values and challenges that differentiate them from for-profits, but what values are specifically unique to your organization? For example, if your organization deals with environmental issues, one of your values may be something along the lines of "the water, the land, the trees, and the animals that inhabit these areas, are valuable and deserve to be protected."

\section{Statement of Ethics}

There are many different forms a statement, or code, of ethics can take. You may want to write out the code, or you may want to develop a grid. You may want to develop one code for the entire organization, or you may

1. This publication is FCS9251, one of a series of the Department of Family, Youth and Community Sciences, Florida Cooperative Extension Service, Institute of Food and Agricultural Sciences, University of Florida. First published: June 2009. Please visit the EDIS Web site at http://edis.ifas.ufl.edu. Reviewed June 2012.

2. Elizabeth B. Bolton, Ph.D., professor of Community Development, Department of Family, Youth and Community Sciences; Florida Cooperative Extension Service; Institute of Food and Agricultural Sciences; University of Florida; Gainesville, Florida 32611 - 0310; and, Anna Guest-Jelley, MFYCS, MA, director of Violence Prevention Program, Peaceful Paths Domestic Abuse Network, also of Gainesville, FL. 
want to develop some statements that apply to everyone, and separate ones that apply only to board, staff, volunteers, etc. Another possibility is to include possible action and program components to the statement of ethics. For example, let's examine the ethical values of responsibility and justice and fairness, as developed by Meneghetti and Seel $(2001$, p. 588). You will notice that the principles in the following example largely apply to the volunteer manager, but could be broadened to apply to more members of the organization.

\section{RESPONSIBILITY}

\section{Accountability}

2. Pursuit of Excellence

Staff Relationships: The Volunteer Manager accepts the responsibility to develop a volunteer program that will enhance the work of the organization's staff

Professional Responsibility: The Volunteer Manager accepts responsibility to contribute to the credibility of the profession in the eyes of those it serves.

Diligence: The Volunteer Manager accepts responsibility to be reliable, careful, prepared, and well informed. Doing One's Best: The Volunteer Manager accepts responsibility to pursue excellence even when resources are limited.

Perseverance: The Volunteer Manager will seek to overcome obstacles to excellence.

\section{JUSTICE AND FAIRNESS}

\section{Procedural Fairness}

Procedural Fairness: The Volunteer Manager assumes the responsibility for an open and impartial process for collecting \& evaluating information that is important for making decisions

2. Impartiality

Impartiality: The Volunteer Manager assumes the responsibility for having impartial and objective standards that avoid discriminatory or prejudicial behaviors

\section{Equity}

Equity: The Volunteer Manager assumes the responsibility to treat all individuals with whom $\mathrm{s} /$ he will work equitably.

A nonprofit could use a chart similar to this in a number of ways. It could evolve to become the organization's actual code of ethics. Or, it could be used for brainstorming and gathering information to develop a more concise code of ethics. The needs of the organization will determine the development process as well as the overall structure of the final document.

\section{References:}

Meneghetti, M.M. \& Seel, K. (2001). Ethics and Values in the Nonprofit Organization. In T. D. Connors (Ed.), The Nonprofit Handbook: Management (pp. 579-609). New York: John Wiley. 